\title{
Erratum: Alberto, R. et al., Wearable Monitoring Devices for Biomechanical Risk Assessment at Work: Current Status and Future Challenges-A Systematic Review. Int. J. Environ. Res. Public Health 2018, 15,2001
}

\author{
Alberto Ranavolo ${ }^{1, *}$, Francesco Draicchio ${ }^{1}$, Tiwana Varrecchia ${ }^{2}$, Alessio Silvetti ${ }^{1}$ and \\ Sergio Iavicoli ${ }^{1}$ \\ 1 Department of Occupational and Environmental Medicine, Epidemiology and Hygiene, INAIL, Via Fontana \\ Candida 1, Monte Porzio Catone, 00078 Rome, Italy; f.draicchio@inail.it (F.D.); al.silvetti@inail.it (A.S.); \\ s.iavicoli@inail.it (S.I.) \\ 2 Department of Engineering, Roma TRE University, Via Vito Volterra 62, 00146 Rome, Italy; \\ tiwana.varrecchia@uniroma3.it \\ * Correspondence: a.ranavolo@inail.it
}

Received: 11 October 2018; Accepted: 2 November 2018; Published: 16 November 2018

Due to an error during production, the first author's name of the published paper [1] was incorrect. The corrected name should be Alberto Ranavolo.

The authors would like to apologize for any inconvenience to the readers caused by this error. The article will be updated and the original will remain on the webpage.

\section{Reference}

1. Alberto, R.; Draicchio, F.; Varrecchia, T.; Silvetti, A.; Iavicoli, S. Wearable Monitoring Devices for Biomechanical Risk Assessment at Work: Current Status and Future Challenges-A Systematic Review. Int. J. Environ. Res. Public Health 2018, 15, 2001. [CrossRef] [PubMed]

(C) 2018 by the authors. Licensee MDPI, Basel, Switzerland. This article is an open access article distributed under the terms and conditions of the Creative Commons Attribution (CC BY) license (http:/ / creativecommons.org/licenses/by/4.0/). 